\title{
Study of the viscoelastic properties of PET by thermally stimulated recovery
}

\author{
N. M. Alves, J. L. Gómez Ribelles, J. F. Mano
}

\begin{abstract}
The conformational chain mobility of semi-crystalline poly(ethylene terephthalate), PET, is studied in the glass transition region by thermally stimulated recovery (TSR). The thermal sampling (TS) experiments are analysed according to a simple VoigtKelvin model. Both the activation energy $\left(E_{\mathrm{a}}\right)$ and the pre-exponential factor follow the usual trends with temperature and present the compensation behaviour, that is discussed in this work. The influence of crystallinity and orientation on the glass transition dynamics is analysed. In particular, the profile of variation of $E_{\mathrm{a}}$ with temperature is found to be very sensitive to these two effects TSR results are compared with the results obtained by differential scanning calorimetry (DSC) and dynamic mechanical analysis (DMA). In addition, this technique was successfully applied to the study of the structural relaxation process of semi-crystallinePET and it was found that the characteristic parameters of the TSR curves vary with the ageing temperature and ageing time. These variations are explained on the basis of the changes verified on the distribution of characteristic times with ageing. PRC/2025

(C) 2003 IoM Communications Ltd. Published by Maney for the Institute of Materials, Minerals and Mining. N. M. Alves and J. F. Mano (for correspondence jmano@dep.uminho.pt) are in the Polymer Engineering Department, University of Minho, Campus of Azurém, 4800-058 Guimarães, Portugal and 3B's Research Group - Biomaterials, Biodegradables and Biomimetics, University of Minho, Campus de Gualtar, 4710-057 Braga, Portugal. J. L. Gómez Ribelles is in the Centre for Biomaterials and Department of Applied Thermodynamics, Universidad Politécnica de Valencia, PO Box 22012, E-46071 Valencia, Spain. Manuscript received 23 April 2003, accepted in final form 26 August 2003.
\end{abstract}

\section{INTRODUCTION}

Thermally stimulated recovery (TSR) has proved to be a suitable technique to study the viscoelastic properties of polymeric systems constituting a complementary tool of the classical dynamic mechanical analysis (DMA) experiments. The time scale for the latter technique, at a given temperature, is defined by the experimental frequency of the stimulus, ${ }^{1,2}$ whereas for TSR it is mainly determined by experimental factors such as the heating rate. For TSR experiments, the equivalent frequency is low $\left(\sim 10^{-2}-10^{-3} \mathrm{~Hz}\right),{ }^{3}$ which is usually associated with high sensitivity. Moreover, TSR offers the possibility to dissect a complex process into quasi-elementary components with the thermal sampling (TS) procedure ${ }^{4-7}$ described in the experimental section.

In 'global' TSR experiments, a static stress is applied to the sample at a sufficiently high temperature $\left(T_{\sigma}\right)$ so that, in the resulting strain $(\mathcal{E})$, all molecular processes are involved. During this creep process, the sample is cooled down to a lower temperature $\left(T_{0}\right)$, where the stress is removed, and at which any recovery could not occur at a reasonable time scale. During a controllable heating, the recovery of the sample strain may be observed as a sudden decrease of the $\varepsilon(T)$ line (or a peak in the $\mathrm{d} \varepsilon / \mathrm{d} T$ plot) so making it possible to detect the distinct molecular motion mechanisms.
Recently, it was demonstrated that TSR experiments could be performed with commercial equipment ${ }^{8}$ enabling experiments to be performed under distinct mechanical excitation modes and allowing for a better comparison between TSR and DMA results. ${ }^{8,9}$ The TSR experiments reported in the literature are usually performed with torsional stresses and, to our knowledge, there is only one report of TSR experiments under threepoint bending. ${ }^{10}$

In the present work, TSR is used as a tool to investigate the viscoelastic properties of semi-crystalline poly(ethylene terephthalate) - PET. In particular, this study focuses on the analysis of the molecular mobility in the glass transition region of PET and the effects of microstructure (namely crystallinity and orientation) on the glass transition dynamics will be discussed. PET is easy to obtain in a fully amorphous state or in different semi-crystalline states. Therefore, it has been frequently used as a model system for studying the influence of crystallinity on the glass transition of the amorphous phase and other physical properties (see, for example, Diego et al. ${ }^{11}$ and Zhao et al. ${ }^{12}$ and references cited therein). Uni-axial or bi-axial drawing could also induce the formation of a crystalline phase in the amorphous material; ${ }^{13,14}$ for example, for high values of uni-axial drawing, the effect is more to align the crystallites with 
the drawing direction rather than to increase the degree of crystallinity. ${ }^{15}$ These facts demonstrate that PET is a suitable material for investigation with different crystallinity and orientation profiles.

The dielectric relaxation spectroscopy of bi-axially stretched PET showed the presence of a secondary $\beta$ relaxation at high frequencies $\left(10^{3}-10^{5} \mathrm{~Hz}\right.$ range) in the temperature interval between $20-100^{\circ} \mathrm{C}$; the main $\alpha$ relaxation appeared as a small peak between $100-120^{\circ} \mathrm{C}$ at frequencies in the range $1-100 \mathrm{~Hz} .{ }^{16}$

In this work, a comparative study of the glass transition dynamics was performed with two different PETs - a semicrystalline isotropic material and a semi-crystalline PET with bi-axial orientation. TSR results are compared with the results of the more conventional DMA technique and differential scanning calorimetry (DSC). In results obtained by thermally stimulated methods (using TS), a linear relationship was found between the thermokinetic parameters when the experiments were carried in the glass transition region. This compensation phenomenon has been extensively discussed in the literature ${ }^{5,17}$ and will also be analysed in this work.

In addition, physical ageing studies on PET were conducted by TSR. Physical ageing, also called structural relaxation, is a kinetic phenomenon that results from the non-equilibrium state characteristic of the glassy state. ${ }^{18}$ The most common situation in which physical ageing is studied is when a material is cooled from above its $T_{\mathrm{g}}$ to an ageing temperature, $T_{\mathrm{a}}$, below $T_{\mathrm{g}}$. Thereafter, during isothermal relaxation at $T_{\mathrm{a}}$, the state of the polymer will approach the equilibrium state and, during this process, the enthalpy, entropy, volume and other physical properties change continuously. In particular, the viscoelastic behaviour of the materials (e.g. creep properties) are greatly modified upon structural relaxation. The present work shows the capability of TSR to monitor the structural relaxation process, providing also a more complete picture of the glass transition dynamics of semi-crystalline PET.

\section{EXPERIMENTAL}

Two distinct samples of PET were analysed: (i) a PET film (Goodfellow, catalogue number ES301300, biaxially oriented) with thickness $0.07 \mathrm{~mm}$; and (ii) a PET bar (Goodfellow, catalogue number ES303010, amorphous) with thickness $1 \mathrm{~mm}$. Both samples were annealed at $\sim 163^{\circ} \mathrm{C}$ for $1 \mathrm{~h}$ to induce crystallinity. As the two materials have different initial orientations, the final structure will be different. With this procedure, no appreciable changes in the microstructure are expected when working repeatedly with the same sample at temperatures below $\sim 160^{\circ} \mathrm{C}$.

Prior to the TSR runs, some experiments of differential scanning calorimetry (DSC) and dynamic mechanical analysis (DMA) were performed in order to characterise the samples - essentially to locate the glass transition temperature and evaluate the crystallinity degree, and also to define the temperature range of interest for the TSR runs.
DSC experiments were conducted on a PerkinElmer DSC7 differential scanning calorimeter with a controlled cooling accessory. The temperature of the equipment was calibrated with indium and lead standards and only the same indium sample was used for the heat flow calibration. The calibrations were performed at $10^{\circ} \mathrm{C} \mathrm{min}^{-1}$. A film sample of $18.613 \mathrm{mg}$ and a bar sample of $18.910 \mathrm{mg}$ were used in the runs.

DMA and TSR experiments were performed on a DMA7e Perkin-Elmer analyser with controlled cooling accessory and high purity helium was used as a purge gas. The PET film was analysed in the tensile mode and a sample with dimensions $0.7 \times 1.3 \times 10 \mathrm{~mm}^{3}$ was cut from the original film. For the PET bar, the three-point bending mode was selected and a sample with dimensions $1 \times 3.3 \times 18 \mathrm{~mm}$ was analysed using a bending platform of $15 \mathrm{~mm}$ and a $5 \mathrm{~mm}$ knife-edge probe tip. The DMA experiments were performed in isochronal conditions from $40-230^{\circ} \mathrm{C}$ at a heating rate of $4^{\circ} \mathrm{C} \mathrm{min}{ }^{-1}$ and a frequency of $1 \mathrm{~Hz}$. A dynamic stress of amplitude $2 \mathrm{MPa}$ and a static stress of amplitude 2.4 $\mathrm{MPa}$ were applied both to the film and the bar in the DMA experiments.

The TSR experiments were carried out with the TS procedure, described as follows: (i) a static stress $\sigma_{0}$ is applied at $T_{\sigma}$ during a time period $t_{\sigma}\left(T_{\sigma}\right.$ varies from experiment to experiment in the region of the global process); (ii) the sample is quenched to $T_{\mathrm{r}}=T_{\sigma}-T_{\mathrm{w}}$ with the mechanical field on; (iii) the stress is removed and the mechanical strain is allowed to recover during a period of time $t_{\mathrm{r}}$; (iv) the sample is quenched to $T_{0}$, well below the temperature region of the global process (say $50^{\circ} \mathrm{C}$ below $T_{\sigma}$ ); and (v) the position of the probe tip, always in contact with the sample, is monitored during a controllable heating ( $\beta$ is the heating rate) from $T_{0}$ up to a final temperature well above $T_{\sigma}$. In all the experiments, $\beta=4^{\circ} \mathrm{C} \min ^{-1}, T_{\mathrm{w}}=3^{\circ} \mathrm{C}, T_{0}=T_{\sigma}-$ $50^{\circ} \mathrm{C}, t_{\mathrm{s}}=4 \mathrm{~min}$ and $t_{\mathrm{r}}=4 \mathrm{~min} . \sigma_{0}$ varied between 2 and $10 \mathrm{MPa}$ for PET3 and between 9 and $49 \mathrm{MPa}$ for PET2. It is assumed that the applied $\sigma_{0}$ values were sufficiently small to ensure the studies in the linear viscoelastic regimen, as the resulting maximum strain was always lower than $1.5 \%$.

In addition to the TSR experiments previously described, physical ageing studies were also carried out for the PET bar. These investigations were also conducted by thermal sampling but before applying the described TS procedure the sample was cooled from the equilibrium state $\left(T>T_{\mathrm{g}}\right)$ to $T_{\sigma}$ and was maintained at this ageing temperature during an ageing time $t_{\mathrm{a}}$.

\section{RESULTS AND DISCUSSION}

\section{Differential scanning calorimetry and dynamic mechanical analysis results}

The DSC runs performed for the two samples are presented in Fig. 1. The first scan of the bar exhibited a $T_{\mathrm{g}}$ at $\sim 74^{\circ} \mathrm{C}$ (defined as the temperature of the midpoint of the heat capacity rise in the transition) and 


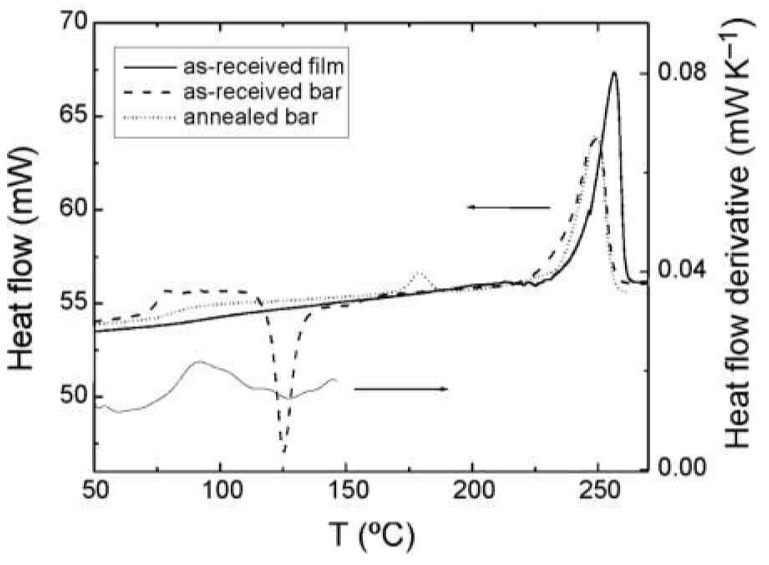

1 Thermograms obtained on heating scans at $10^{\circ} \mathrm{C}$ $\mathrm{min}^{-1}$ for the as-received PET film and for the asreceived and annealed $\left(165^{\circ} \mathrm{C}\right.$ for $\left.1 \mathrm{~h}\right)$ PET bar. For the as-received film, the derivative of the heat flow curve between $50-150^{\circ} \mathrm{C}$ is also shown

a well-pronounced cold crystallisation peak that appears after the glass transition, indicating that this sample should be nearly amorphous. After annealing the bar at $163^{\circ} \mathrm{C}$ for $1 \mathrm{~h}$, crystallinity is induced as shown by a less-pronounced glass transition and the absence of a cold crystallisation peak. A small melting peak $\left(\Delta H_{\mathrm{m}}=3.2 \mathrm{~J} \mathrm{~g}^{-1}\right)$ appears at $\sim 175^{\circ} \mathrm{C}$ besides the melting peak located in the usual temperature range for PET (in this case $T_{\mathrm{m}} \sim 237^{\circ} \mathrm{C}$ and $\Delta H_{\mathrm{m}}=37.8 \mathrm{~J} \mathrm{~g}^{-1}$ ). The presence of multiple melting peaks in PET has been frequently observed by DSC (see, for example, Lu and $\mathrm{Hay}^{19}$ and Sauer et $a l^{20}$ and references cited therein). Several interpretations for this behaviour have been proposed including: (i) the occurrence of melting/ re-crystallisation and re-melting; (ii) morphological changes such as a modification from chain-folded lamellar crystals to fringed micelle crystals; (iii) lamellae thickening and crystal perfecting; or (iv) an explanation on the basis of the branching lamella model for spherulites Recently, a detailed study has been performed $^{21}$ showing the complexity of the melting behaviour of PET. Depending on the experimental conditions chosen for crystallising an initially amorphous sample, namely isothermal or non-isothermal crystallisation, thermal history and heating rate, one, two or even three melting peaks could be detected. Considering the case of isothermal crystallisation and when two peaks are observed, as occurs in the present work, these are attributed to the presence of a dual lamella thickness distribution originating during crystallisation. ${ }^{21}$ Usually, the melting peak at lower temperature appears at $\sim 10^{\circ} \mathrm{C}$ above the annealing temperature, exactly as happened in our case. So the small melting peak detected in Fig. 1 for the annealed bar should be related to the secondary crystallisation process (i.e. with the crystallisation of amorphous material between the primary lamellae) and could be attributed to the melting of secondary lamellae that are obviously thinner than the primary lamellae and melt at lower temperature. The second peak is associated with the melting of the primary lamellae which form initially in the primary crystallisation stage. Kong and $\mathrm{Hay}^{21}$ show a third melting peak appearing at a higher temperature during some experimental conditions; this was explained by the melting of the primary lamellae that have thickened by re-crystallisation and/or probably by extension of the chains in the primary lamellae along the thickness direction.

For the annealed sample, the glass transition is very broad covering the interval $70-110^{\circ} \mathrm{C}\left(T_{\mathrm{g}} \sim 81^{\circ} \mathrm{C}\right)$, which reflects the influence of the crystalline regions. The increase of crystallinity broadens the glass transition of semi-crystalline PET as has been detected by $\mathrm{DSC}^{22}$ and dielectric spectroscopy. ${ }^{23}$ In fact, for aged PET bar samples with lower crystallinity than the sample studied in this work, double peaks have been found by DSC revealing the presence of two amorphous phases ${ }^{22}$ and consequently two separated glass transition processes.

For the film sample, the runs - either scanned as received or after annealing at $163^{\circ} \mathrm{C}$ for $1 \mathrm{~h}$ (not shown)were almost identical, the only difference being a small melting peak $\left(\Delta H_{\mathrm{m}}=1.4 \mathrm{~J} \mathrm{~g}^{-1}\right)$ in the region of the thermal treatment besides the melting peak at $T_{\mathrm{m}}$ $\sim 243^{\circ} \mathrm{C}$. The melting temperature of the film is somewhat higher than the one corresponding to the bar indicating a more perfect crystalline structure or higher molecular orientation. In this case, it was very difficult to visualise the glass transition attributable to a combined effect of crystallinity and orientation, which leads to a very small $\Delta C_{\mathrm{p}}$, almost undetectable by DSC. As referred to in the introduction, both crystallinity and orientation change the glass transition dynamics, but of course when both crystallinity and orientation effects are present as in the film, it is very difficult to separate the influence of these two effects on the mobility of the amorphous phase. The derivative of the heat flux curve of the first heating indicated a $T_{\mathrm{g}}$ value of $\sim 93^{\circ} \mathrm{C}$ but, of course, this is just an approximate value.

The degree of crystallinity $\left(X_{c}\right)$ could be estimated from DSC by using the equation:

$$
X_{\mathrm{c}}=\frac{\Delta H_{\mathrm{m}}-\Delta H_{\mathrm{c}}}{\Delta H_{\mathrm{m}}^{0}}
$$

where $\Delta H_{\mathrm{m}}$ is the measured enthalpy of fusion of the sample, $\Delta H_{\mathrm{m}}^{0}$ is the enthalpy of fusion of the completely crystalline material $\left(140 \mathrm{~J} \mathrm{~g}^{-1}\right.$ for $\mathrm{PET}^{24}$ ) and $\Delta H_{\mathrm{c}}$ is the enthalpy of cold crystallisation observed during the run.

For the annealed bar, $\Delta H_{\mathrm{m}}=41 \mathrm{~J} \mathrm{~g}^{-1}$ and $\Delta H_{\mathrm{c}}=0 \mathrm{~J} \mathrm{~g}^{-1}$ which leads to $X_{\mathrm{c}}=29 \%$. and for the annealed film $\Delta H_{\mathrm{m}}$ $=50 \mathrm{~J} \mathrm{~g}^{-1}, \Delta H_{\mathrm{c}}=0 \mathrm{~J} \mathrm{~g}^{-1}$ and $X_{\mathrm{c}}=36 \%$. Thus, it seems that the film has a higher crystallinity than the bar. This was expected because both samples were subjected to an equal thermal treatment and the film was already oriented. Studies of the non-crystalline phase of drawn PET revealed the appearance of a highly oriented amorphous phase that acts as a precursor for extended chain crystallisation, ${ }^{15}$ that in fact would result in a higher crystallinity degree when samples subjected to the same thermal treatment are compared. 


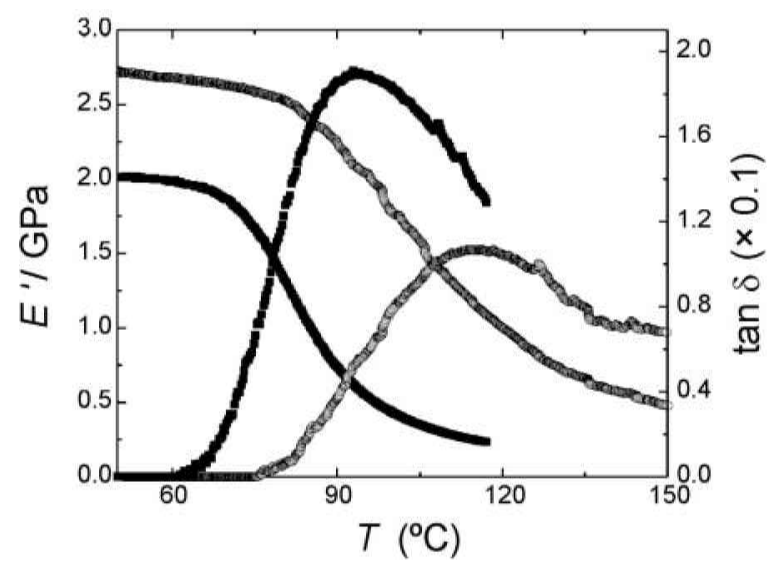

2 Elastic modulus $\left(E^{\prime}\right)$ and loss factor $(\tan \delta)$ as a function of temperature obtained at $1 \mathrm{~Hz}$ and $4^{\circ} \mathrm{C}$ $\mathrm{min}^{-1}$. Open symbols, film; solid symbols, bar

The disappearance of the cold-crystallisation peak in the DSC scan of the film is certainly related to the presence of this strain-induced crystallised phase. ${ }^{24}$ Note that the bar as received is in fact almost nearly amorphous: $X_{\mathrm{c}}=$ $4 \%\left(\Delta H_{\mathrm{m}}=41 \mathrm{~J} \mathrm{~g}^{-1}\right.$ and $\left.\Delta H_{\mathrm{c}}=35 \mathrm{~J} \mathrm{~g}^{-1}\right)$.

The increase of the specific heat capacity at the glass transition $\Delta C_{\mathrm{p}}\left(T_{\mathrm{g}}\right)$, defined by the difference between the specific heat capacities between the liquid and the glassy states at $T_{\mathrm{g}}$, is a measure of the amorphous fraction. This amorphous fraction could be calculated from the relationship:

$$
X_{\mathrm{am}}=\frac{\Delta C_{\mathrm{p}}\left(T_{\mathrm{g}}\right)}{\Delta C_{\mathrm{p} 0}\left(T_{\mathrm{g}}\right)}
$$

where $\Delta C_{\mathrm{p} 0}\left(T_{\mathrm{g}}\right)$ is the specific heat capacity at the glass transition for the completely amorphous sample. For PET, the measured values of $\Delta C_{\mathrm{p} 0}\left(T_{\mathrm{g}}\right)$ by DSC are usually found between $0 \cdot 30-0 \cdot 36 \mathrm{~J} \mathrm{~g}^{-1} \mathrm{~K}^{23,26}$

For the bar, $\Delta C_{\mathrm{p}}\left(T_{\mathrm{g}}\right)$ is $0.13 \mathrm{~J} \mathrm{~g}^{-1} \mathrm{~K}$ for an annealed sample and for the almost amorphous material (first running) $\Delta C_{\mathrm{p} 0}\left(T_{\mathrm{g}}\right)=0.31 \mathrm{~J} \mathrm{~g}^{-1} \mathrm{~K}$; applying Equation 2 gives $X_{\mathrm{am}}=42 \%$. As $X_{\mathrm{c}}=30 \%$, the behaviour of this sample can not be described by a two-phase model where $X_{c}+X_{a m}=100$. For the film, as the glass transition is almost undetectable, it was not possible to calculate the corresponding $\Delta C_{\mathrm{p}}\left(T_{\mathrm{g}}\right)$ in order to estimate the amorphous fraction before and after annealing.

The results obtained for the bar indicate that $\Delta C_{\mathrm{p}}\left(T_{\mathrm{g}}\right)$ is smaller than would be expected from the crystallinity. This behaviour has been found in some semi-crystalline polymers, including PET, by several authors (see, for example, Menczel and Wunderlich ${ }^{27}$, Seyler $^{28}$ and Kattan et $a l^{29}$ ). To describe such behaviour, the existence of a rigid amorphous phase was proposed by Ishida et al. ${ }^{30}$ and by Wunderlich and co-workers, ${ }^{31-33}$ respectively, for dielectric and calorimetric investigations, to be distinguished from crystals and a mobile(undisturbed) amorphous phase. So, for the PET bar, a rigid amorphous phase that does not participate in the glass transition sample should be included in the description of the system, and one should write $X_{\mathrm{c}}+X_{\mathrm{am}}+X_{\mathrm{ar}}=100$. For the film, although it was not possible to estimate the amorphous fraction before and after annealing, it can be said that the mobile amorphous phase should be very small, i.e. the amorphous fraction present in this PET is essentially rigid, possibly due to orientation effects, which would explain an almost undetectable glass transition by DSC. Many other authors agree with the existence of a rigid amorphous phase to explain the behaviour of PET, not only in calorimetric investigations, but also in dielectric, mechanical and thermally stimulated depolarisation current studies. ${ }^{23,26,29,34,35} \mathrm{U}$ sually, the rigid amorphous phase in semi-crystalline polymers is the result of restrictions of molecular mobility due to the fixation of the polymer chain at the surface of the crystalline lamellae.

It should be pointed out that other authors supposed that the differences from the two-phase model are attributed to a wrong determination of crystallinity. ${ }^{36}$ However, the same procedure of estimating the amorphous and crystalline fractions (that was followed in this work), when applied to secondary relaxations, show that they follow a two-phase model as expected for local motions which are almost unaffected by the restrictions of the crystalline lamellae..$^{29,35}$

As it was not possible to visualise clearly the glass transition region of the film by DSC, additional DMA experiments were conducted on the annealed samples. The DMA results are presented in Fig. 2 and showed a higher temperature of the maximum of the loss factor $(\tan \delta)$ for the film than for the bar. This indicates a higher $T_{\mathrm{g}}$ for the former that could be explained by the presence of more restrictions to segmental mobility in the amorphous domains imposed by the crystalline regions; however, it can be explained by orientation effects as well. ${ }^{13,14}$ In fact, the differences in the crystallinity are not so high, as shown by DSC, to justify such a difference in the $T_{\mathrm{g}}$ values. Molecular orientation usually produces a hardening of the material even when its crystallinity degree does not suffer changes, ${ }^{37}$ so the orientation present in the film also leads to a more constrained environment for the amorphous regions. The film has a lower $\tan \delta$, which means a smaller amorphous fraction for this sample, and a higher elastic modulus $(E)$ in the glassy region as expected for an oriented and more crystalline sample. ${ }^{13,14}$

\section{Thermally stimulated recovery results}

TS experiments were performed in the glass transition region for both samples. Based on the previous experiments described above, different $T_{\sigma}$ values were chosen, within the temperature ranges $62.1^{\circ} \mathrm{C}<T_{\sigma}<$ $136.1{ }^{\circ} \mathrm{C}$ for the film and $58.9^{\circ} \mathrm{C}<T_{\sigma}<122.4^{\circ} \mathrm{C}$ for the bar. Fig. 3a,b shows some of those experiments represented in terms of the absolute derivative of the measured strain recovery as a function of temperature. These curves show a peak with the maximum appearing at $T=T_{\max }$ and are shifted to higher temperatures as $T_{\sigma}$ increases. The height of the peak increases as $T_{\sigma}$ 

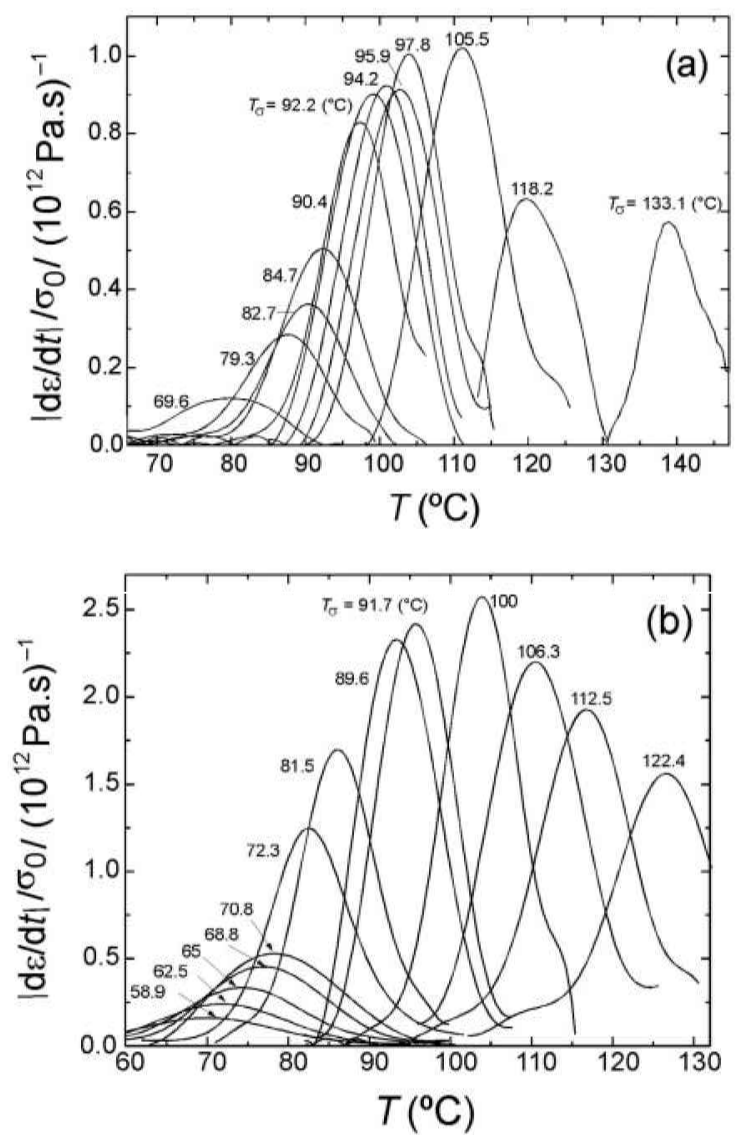

3 Absolute derivative of the measured strain recovery as a function of temperature for (a) the film and (b) the bar. The experimental conditions were $\beta=4^{\circ} \mathrm{C} \mathrm{min}^{-1}, T_{\mathrm{w}}=3^{\circ} \mathrm{C}, T_{0}=T_{\sigma}-50^{\circ} \mathrm{C}, t_{\sigma}=t_{\mathrm{r}}=4$ min and $62.1{ }^{\circ} \mathrm{C}<T_{\sigma}<136.1^{\circ} \mathrm{C}$ for the film and $58.9^{\circ} \mathrm{C}<T_{\sigma}<122.4^{\circ} \mathrm{C}$ for the bar. For clarity, not all the performed experiments are plotted

increases due to the progressive activation of more relaxation processes for a given time, as it is typically seen in this kind of experiment. ${ }^{1,2}$ Above $T_{\mathrm{g}}$, the height tends to stabilise and usually a decrease is observed above the temperature at which the activation energy begins to decrease (described later, see Fig. 5). This occurs because the retardation times become smaller as the temperature goes to the elastomeric plateau and times in the region of TSR ( 100 s) become more scarce (i.e. more in the lower value tail of the retardation time distribution).

The intensity of the peaks is lower for the film than for the bar reflecting a more crystalline/oriented sample with a smaller amorphous phase and hence with a less intense $\alpha$-process. The decrease of the peak area with increasing orientation was also detected by thermally stimulated depolarisation currents (TSDCs) ${ }^{29}$ for PET samples with different drawing ratios (from 1-7.2).

Each TS curve can be analysed as a thermally stimulated mechanical recovery process of an elementary mechanism. The Voigt-Kelvin model can be used to predict the dependence of the strain upon time or temperature. The corresponding constitutive equation is:

$$
\tau(T) \frac{\mathrm{d} \varepsilon(t)}{\mathrm{d} t}=\frac{\sigma_{0}}{E}-\varepsilon(t)
$$

where $\sigma_{0}$ is the static strain, $E$ is the Young modulus of the spring element and $\tau(T)$ is the retardation time of the process. The characteristic time is $\tau=\eta / E$, where $\eta$ is the viscosity of the Newtonian dashpot which is in parallel with the elastic element.

Applying Equation 3 to the mechanical recovery $\left(\sigma_{0}\right.$ $=0$ ) during heating at a constant rate $\beta$, the temperature dependence of the strain is:

$$
\varepsilon(T)=\varepsilon_{0} \exp \left[-(1 / \beta) \int_{T_{0}}^{T} \frac{\mathrm{d} T}{\tau(T)}\right]
$$

where $\varepsilon_{0}=\varepsilon\left(T_{0}\right)$.

It can be easily be found from Equation 4 that:

$$
\tau(T)=-\frac{1}{\beta} \frac{\varepsilon(T)}{\mathrm{d} \varepsilon(T) / \mathrm{d} T}
$$

Equation 5 allows the calculation of the temperature dependence of the retardation time directly from the experimental results. This procedure, often called the Bucci or BFG method, was first derived for the treatment of TSDC data. ${ }^{38}$ The calculation of $\tau(T)$ by the BFG method is carried out between $\sim T_{\max }-30$ and $\sim T_{\max }$, where $T_{\max }$ is the temperature of the maximum of the peaks presented in Fig. 3. More details on the treatment of TSR results may be found elsewhere. ${ }^{8}$ In Fig. $4 \mathrm{a}, \mathrm{b}$ are depicted the temperature dependence of the retardation time for the two samples.

Usually, it is assumed that $\tau(T)$ presents an Arrhenius behaviour:

$$
\tau=\tau_{0} \exp \left(E_{\mathrm{a}} / R T\right)
$$

where $E_{\mathrm{a}}$ is the apparent activation energy, $\tau_{0}$ is the preexponential factor and $R$ is the perfect gas constant. The thermokinetic parameters $\left(E_{\mathrm{a}}\right.$ and $\left.\log \tau_{0}\right)$ are obtained by fitting $\ln \tau(T)$ vs $1 / T$. In Fig. 5 is shown the variation of the activation energy with temperature for the two samples calculated with the described method. The high values of $E_{\mathrm{a}}$ for these studies carried in the glass transition region may be explained on the basis of cooperative conformational re-arrangements within the macromolecular segments and $E_{\mathrm{a}}$ increases with increasing temperature reflecting the greater cooperativity and complexity of the involved motions. For the film, a nearly constant value for $E_{\mathrm{a}}$ is obtained at low temperatures, which may be explained by the Adam-Gibbs theory that states an Arrhenius behaviour for the chain mobility in the glassy state. ${ }^{39}$ The increase of $E_{\mathrm{a}}$ seen in both samples is a consequence of the transition between an Arrhenius and a Vogel regimen ${ }^{40}$ described by the Vogel-Fulcher-Tamman-Hesse (VFTH) equation:

$$
\tau(T)=\tau_{0} \exp \left(\frac{B}{T-T_{0}}\right)
$$

where $\tau_{0}$ is a pre-exponential factor and $B$ and $T_{0}\left(T_{0}<\right.$ $T_{\mathrm{g}}$ ) are specific adjustable parameters. Above $T_{\mathrm{g}}$, the 

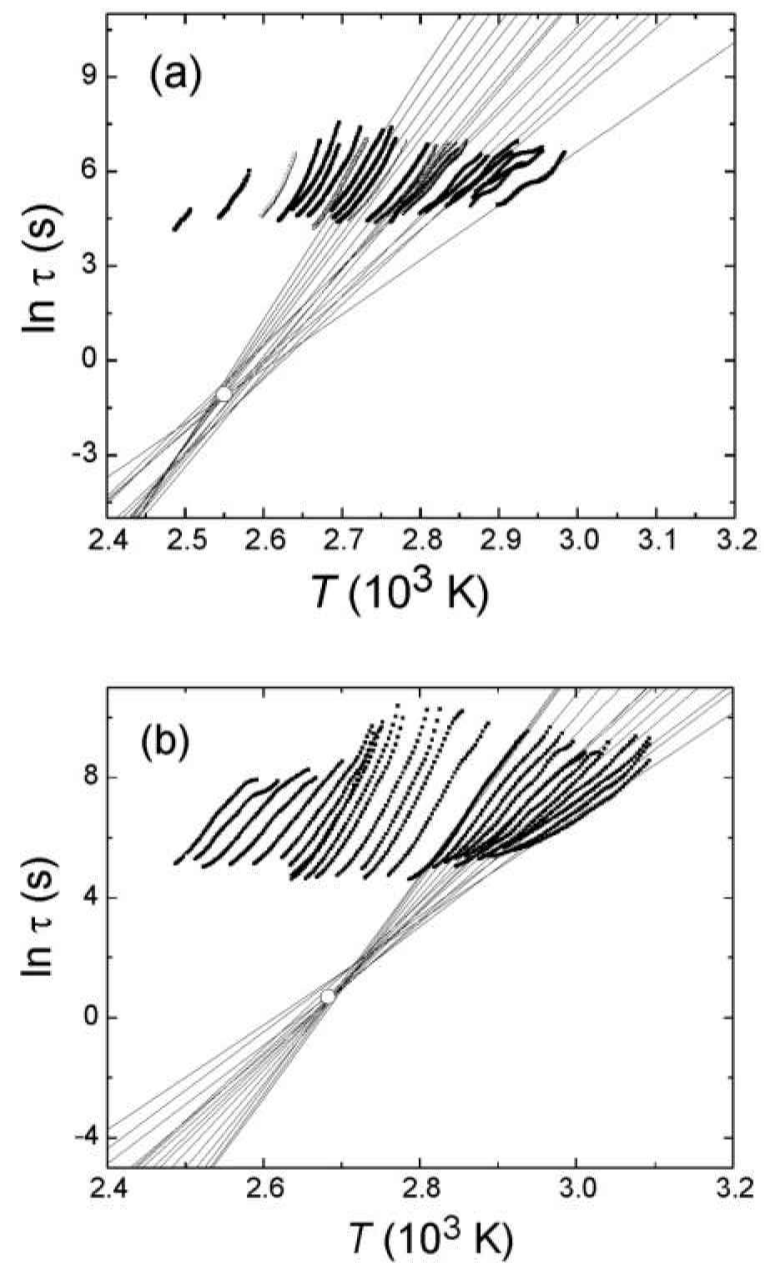

4 Arrhenius plot of the TS data in the glass transition region. (a) Film; (b) bar. In the glassy state, the Arrhenius lines (solid lines) converge to the compensation point (circle)

materials are in thermodynamic equilibrium and $E_{\mathrm{a}}$ decreases as the temperature increases as predicted by the VFTH equation. ${ }^{41}$ It is interesting to note that the maximum values of $E_{\mathrm{a}}$ obtained in this work, $354 \mathrm{~kJ}$ $\mathrm{mol}^{-1}$ for the film and $388 \mathrm{~kJ} \mathrm{~mol}^{-1}$ for the bar, are in agreement to the value found in the literature for semicrystalline PET by TSDC $\left(\sim 378 \mathrm{~kJ} \mathrm{~mol}^{-1}\right),{ }^{42}$ while for amorphous PET the maximum value of $E_{\mathrm{a}}$ is usually higher $\left(\sim 457 \mathrm{~kJ} \mathrm{~mol}^{-1}\right){ }^{42}$

As discussed above, although both are semicrystalline PET samples, the film should have a higher crystallinity than the bar and there is the additional effect of orientation in the film that also broadens and shifts the glass transition to higher temperatures, ${ }^{13,33}$ so the $T_{\mathrm{g}}$ of the film is higher than the $T_{\mathrm{g}}$ of the bar. As a result, in Fig. 5 the transition from the Arrhenius to the Vogel behaviour occurs at higher temperatures and is broader for the film which could indicate a broader distribution of characteristic times. ${ }^{22}$ So, the different profile of variation of $E_{\mathrm{a}}$ with temperature and the slightly distinct values of $E_{\mathrm{a}}$ found at the transition from the Arrhenius to the Vogel behaviour obtained

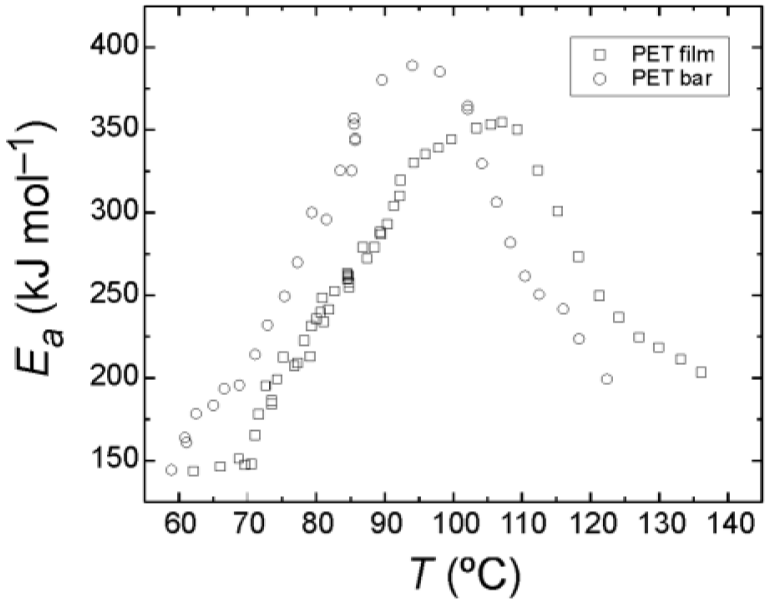

5 Activation energies as a function of temperature for the PET film (open squares) and the PET bar (open circles) calculated in both the glassy and equilibrium states from TS experiments

for these two PET samples could be essentially attributed to differences in both crystallinity and orientation. The $T_{\mathrm{g}}$ of the film $\left(107^{\circ} \mathrm{C}\right)$, measured by TSR as the temperature of the maximum activation energy (Fig. 5), is $\sim 12^{\circ} \mathrm{C}$ higher than the $T_{\mathrm{g}}$ of the bar $\left(95^{\circ} \mathrm{C}\right)$, which is in agreement with the difference found by DSC. Moreover, by using the TSR technique, in contrast to DSC the $T_{\mathrm{g}}$ of the film is clearly detectable, so this technique is very sensitive for locating the glass transition even for samples with crystallinity/orientation effects. Of course, the absolute values are different as is usual when comparing glass transition temperatures measured by different thermal techniques where the measured physical property to evaluate $T_{\mathrm{g}}$ changes and the temperature programmes are distinct.

It can be seen that the film has a comparatively lower activation energy than the bar, an identical behaviour to the one found by other authors ${ }^{43}$ in a study of stretched and unstretched samples of PET by thermally stimulated currents (TSC) and TSDC. According to Sauer and $\mathrm{Kim},{ }^{44}$ the lower values of $E_{\mathrm{a}}$ are an indication that the polymer chains are more homogeneous in terms of their structural regularity and/or composition. In our case, the effect of different compositions is not relevant; however, the structural regularity in the oriented film should be higher than in the bar and this could be the reason for the lower values of $E_{\mathrm{a}}$ exhibited by the film.

The lower activation energy of the film when compared with the value obtained for the bar can also be analysed in terms of the fragility concept first introduced by Angell. ${ }^{45}$ Fragility is a measure of the rate at which the structural characteristic times, $\tau$ (or related properties, such as the shear viscosity $\eta$ ), decreases with increasing temperature around $T_{\mathrm{g}}$ when plotted on a normalised $T_{\mathrm{g}} / T$ plot. Previously, it was shown that TSR can be used to estimate the fragility of a given material. ${ }^{46}$ As shown here, ${ }^{46}$ a higher activation 
energy associated with a lower $T_{\mathrm{g}}$ results in a higher fragility. So, from the results shown in Fig. 5, it can be concluded that the bar is more fragile than the film, which means that the non-Arrhenius character of the temperature-dependent behaviour is more pronounced for this sample.

It can be seen in Fig. 4a,b that the Arrhenius lines of the TS curves obtained in the glass transition region but below $T_{\mathrm{g}}$ tend to converge to a single point, usually referred to in the literature as the compensation point, characterised by a compensation temperature $T_{c}$ and a compensation time $\tau_{c}$. This compensation phenomenon can also be seen by a nearly perfect linear relationship between the thermokinetic parameters $E_{\text {a }}$ and $\log \tau_{0}$ (or equivalently by a linear relationship between the activation enthalpy and the activation entropy from the Eyring analysis ${ }^{17}$ ).

The compensation phenomenon has been extensively discussed in the literature (see, for example, Lacabanne et $a l .{ }^{5}$ and Moura Ramos et $a l .{ }^{17}$ and references cited therein) and always appears in TSR and TSDC results when the studies are carried out in the glass transition region. This kind of behaviour is not unique to TSDC and TSR results for polymeric systems, but has also been detected in studies on the kinetics or equilibrium behaviour of chemical and biological processes. ${ }^{47}$

Fig. 6 shows the compensation plot for the film and for the bar. From the linear fitting of the results, the two compensation parameters $\tau_{\mathrm{c}}$ and $T_{\mathrm{c}}$ can be derived:

$$
\log \tau_{0, \mathrm{i}}=\log \tau_{\mathrm{c}}-\left[E_{\mathrm{a}, \mathrm{i}} / \ln (10) R T_{\mathrm{c}}\right]
$$

Substitution of this equation into the Arrhenius equation (Eq. 6) leads to:

$$
\ln \tau=\ln \tau_{\mathrm{c}}+\frac{E_{\mathrm{a}}}{R}\left(\frac{1}{T}-\frac{1}{T_{\mathrm{c}}}\right)
$$

which is known as the compensation law. ${ }^{4}$

These parameters are $119^{\circ} \mathrm{C}$ and $0 \cdot 3 \mathrm{~s}$ for the film and $100^{\circ} \mathrm{C}$ and $2 \mathrm{~s}$ for the bar. Unoriented and biaxially oriented films of PET have been compared for exploring the influence of molecular orientation and crystallinity $^{5,43,48}$ in the compensation parameters. However, the results are not conclusive because in some studies there seems to be a variation ${ }^{43,48}$ with these factors but in another study ${ }^{5}$ the influence was not significant. In these studies, ${ }^{5,43,48} T_{\mathrm{c}}$ is between $5-30^{\circ} \mathrm{C}$ above $T_{\mathrm{g}}$, as in our samples, and the decrease in $\tau_{c}$ with increasing crystallinity/orientation, that also occurs with our samples, was interpreted as a decrease of the size of the moving units. ${ }^{43}$

In fact, the practical significance of the compensation parameters is difficult to interpret and, to date, no consistent theory has offered an unambiguous explanation for their physical origin. Some authors have argued that this phenomenon does not have a true physical origin but rather it is a result of statistical error propagation. ${ }^{49,50}$ However, in some cases, ${ }^{51,52}$ this phenomenon could not be described simply as an error

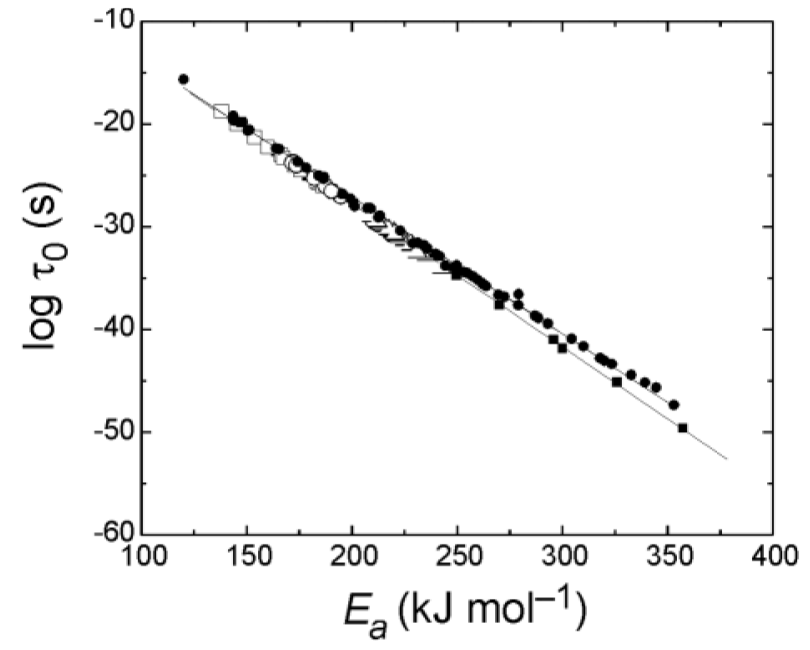

6 Compensation plot for the PET bar (solid squares) and the PET film (solid circles). The solid lines are linear fittings of these data. In this figure are also represented the ageing studies for the PET bar: the open symbols are for the thermokinetic parameters of the aged TS results of Fig. 7, obtained at three $T$ values (squares, $63.9^{\circ} \mathrm{C}$; circles, $68.7^{\circ} \mathrm{C}$; and triangles, $73.7^{\circ} \mathrm{C}$ )

propagation. It was suggested that the compensation phenomenon cannot be considered as a basic feature of the glass transition relaxation but that it is just a mathematical consequence of a fundamental relationship between the activation Gibbs energy and temperature. ${ }^{17}$ Another argument supporting the lack of a physical basis for this phenomenon is that it predicts at the compensation temperature (usually observed $5-30^{\circ} \mathrm{C}$ above $T_{\mathrm{g}}$ for a variety of materials not just $\mathrm{PET}^{17,53}$ ) that all the characteristic times of the different processes are the same which means that at $T_{\mathrm{c}}$ the system behaves as an elementary process. Of course this is not an acceptable possibility in the case of most polymeric systems. In fact, the existence of a distribution of characteristic times at $T_{\mathrm{c}}$ was demonstrated by $\mathrm{Read}^{54}$ for an isotactic polypropylene studied by mechanical spectroscopy and also for PET. ${ }^{41}$

In a previous study, ${ }^{8}$ it was shown that the direct fit method, often applied to the calculation of the thermokinetic parameters, pointed to an intrinsic compensation effect between the activation energy and the pre-exponential factor in the equation that describes thermally stimulated recovery during heating. The results shown in Fig. 6 also seem to indicate that the compensation phenomenon is, in fact, a pure mathematical consequence of the underlying process and does not have a true physical origin, because, for the two PET samples with distinct crystallinity and orientation, it can be seen that the compensation lines tend to converge to the same point.

\section{Physical ageing studies}

The glass transition of the annealed PET bar lies between $70-110^{\circ} \mathrm{C}$ as measured by DSC (see above), so 

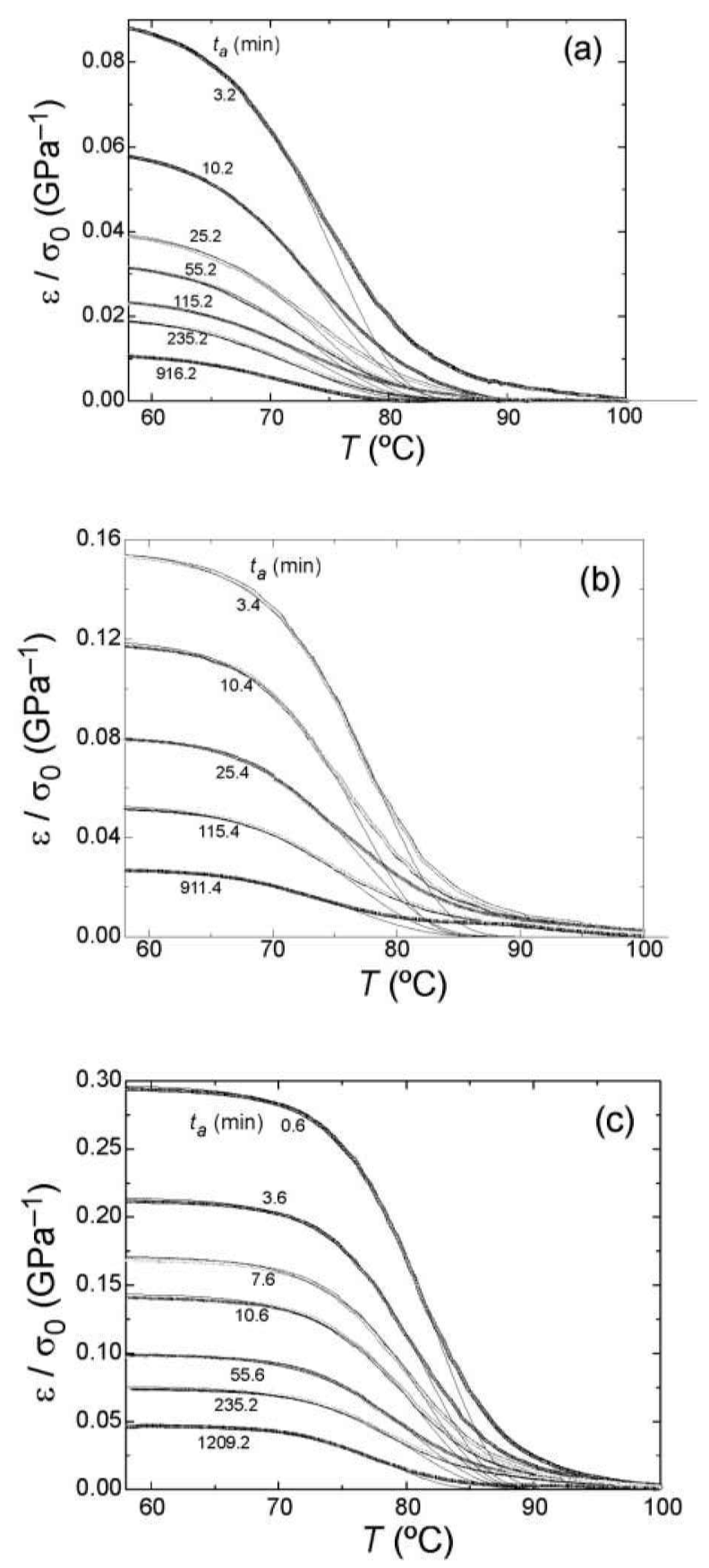

7 TS curves obtained after different ageing times $(t)$ at: (a) $T_{a}=63.9^{\circ} \mathrm{C}$; (b) $T_{a}=68.7^{\circ} \mathrm{C}$; and (c) $T_{a}=73.7^{\circ} \mathrm{C}$ for the PET bar

three ageing temperatures $\left(T_{\mathrm{a}}\right)$ below $T_{\mathrm{g}}$ were selected to perform the TS runs $-63.9^{\circ} \mathrm{C}, 68 \cdot 7^{\circ} \mathrm{C}$ and $73 \cdot 7^{\circ} \mathrm{C}$. For each ageing temperature, the TS experiments were performed after several ageing times $\left(t_{\mathrm{a}}\right)$. The TS experiments for the these temperatures are presented in Fig. $7 \mathrm{a}-\mathrm{c}$.

The total strain of each elementary process ( $\varepsilon_{0}$ in Eq. 4$)$ is plotted against the ageing time $t_{\mathrm{a}}$ in Fig. 8a for the three ageing temperatures. It is observed a decrease in $\varepsilon_{0}$ as $t_{\text {a }}$ increases that reflects a stiffening of the material with physical ageing. It has been known since Struik's first works $^{55}$ that the ageing process shifts the distribution of characteristic times towards longer times. So $\varepsilon_{0}$, that represents the short time creep occurring at $T_{\text {a }}$ and the partial recovery at $T_{\mathrm{r}}$ decreases as the ageing time increases due to the shift of the creep curves to longer times.

In Fig. $8 \mathrm{~b}, T_{\max }$ (i.e. the inflexion temperature of $\varepsilon(T))$ is represented as a function of $t_{\mathrm{a}}$. The increase in $t_{\mathrm{a}}$ leads to a decrease of $T_{\max }$ that may be regarded as a shift of the elementary processes to lower temperatures during ageing. The variation in $E_{\mathrm{a}}$ and $\log \tau_{0}$ with $t_{\mathrm{a}}$ for the three ageing temperatures can be seen in Fig. $8 \mathrm{c}, \mathrm{d}$. A decrease in $E_{\mathrm{a}}$ and an increase in $\log \tau_{0}$ as $t_{\mathrm{a}}$ increases is observed. As seen above, the opposite variation in $E_{\mathrm{a}}$ and $\log \tau_{0}$ is typical of the compensation behaviour. Although the magnitude of the variation of $T_{\max }, E_{\mathrm{a}}$ and $\log \tau_{0}$ is small, it is quite consistent for all ageing temperatures and has already been found in another system studied in our laboratory. ${ }^{9}$ In this study, ${ }^{9}$ these variations are explained in further detail. The ageing effects detected in the mentioned parameters are smaller than the ones observed previously, ${ }^{9}$ because the PET analysed in this work is a semi-crystalline material, hence has a smaller fraction of amorphous phase than the thermoset studied before. ${ }^{9}$

It is clear that with the thermomechanical programme of the TS procedure (described in the experimental section), a narrow window within the distribution of retardation times can be selected. The decrease in $T_{\max }$ with $t_{\mathrm{a}}$ was interpreted in terms of the shift of the isolated retardation times towards lower values in the TS experiments, that results in a recovery of the strain during heating appearing at lower temperatures as the ageing time increases.

It is assumed that the observed decrease in $E_{\mathrm{a}}$ with increasing $t_{\mathrm{a}}$ is closely related to the decrease detected in $T_{\max }$. It should be pointed that the thermokinetic parameters and $T_{\max }$ are not independent variables as can be easily demonstrated (assuming an Arrhenius behaviour) from the analysis of Equations (4) and (5):

$$
\tau_{0} \exp \left(\frac{E_{\mathrm{a}}}{R T_{\max }}\right)=\frac{R T_{\max }^{2}}{\beta E_{\mathrm{a}}}
$$

In some analyses where ageing studies were conducted by thermally stimulated depolarisation currents (TSDCs), the equivalent dielectric technique of TSR, an increase in the temperature of the depolarisation peak and the activation energy with increasing ageing time for polyetherimide and semi-crystalline PET was reported. ${ }^{11,56,57}$ However, the discrepancy between the results obtained by the two techniques may be apparent because there are differences in the TS procedures followed by these authors and by ourselves which means that the two charging profiles activate different retardation time windows.

The thermokinetic parameters change with ageing as these results demonstrated. However, it can be observed from Fig. 6 that all the results of the ageing experiments lie on the compensation line of the nonageing experiments presented above. This means that the compensation effect does not depend on the previous thermal history undergone by the material 

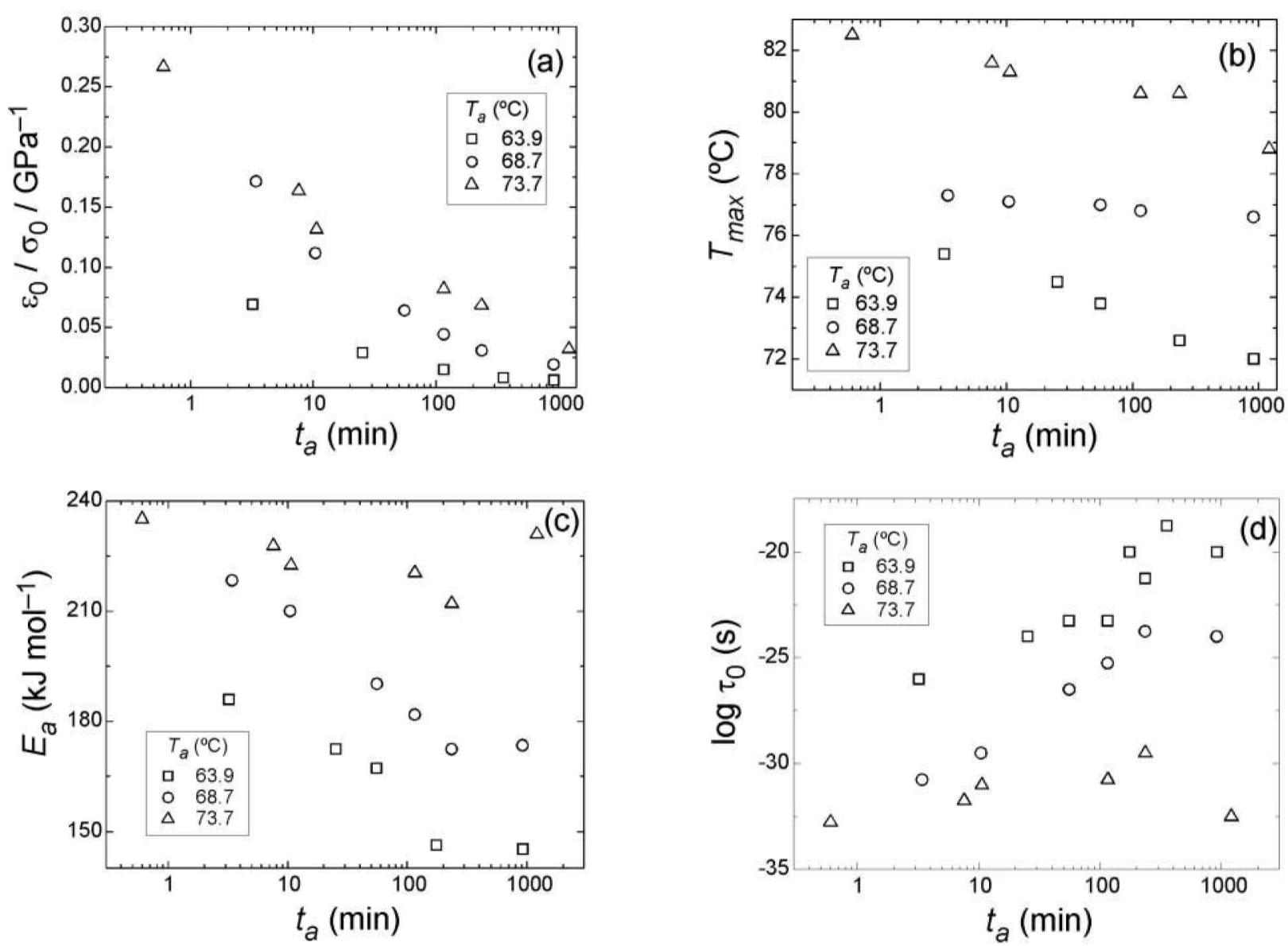

8 Dependence of the different parameters of the TS curve obtained after different ageing temperatures and times for the PET bar. (a) Normalised maximum strain recovered; (b) inflexion temperature; (c)activation energy; and (d) pre-exponential factor

below $T_{\mathrm{g}}$. These observations also seem to support the idea of a lack of physical meaning of the compensation parameters and the compensation phenomenon itself discussed above.

\section{CONCLUSIONS}

The influence of crystallinity and orientation on the glass transition dynamics of PET has been studied mainly by TSR. It was observed that the intensity of the TSR peaks is lower as crystallinity and/or orientation increases, reflecting a smaller amorphous phase and hence a less intense $\alpha$-process.

The variation in $E_{\mathrm{a}}$ with temperature seen in both samples is a consequence of the transition between an Arrhenius and a Vogel regimen. The different profile of variation of $E_{\mathrm{a}}$ with temperature and the distinct values of $E_{\mathrm{a}}$ found at the transition from the Arrhenius to the Vogel behaviour obtained for these two PET samples could be essentially attributed to differences in both crystallinity and orientation. The $T_{\mathrm{g}}$ of the oriented semi-crystalline film measured by TSR is higher than the $T_{\mathrm{g}}$ of the isotropic semi-crystalline bar, which is in agreement with the results found by DSC and DMA. By comparing the values of $E_{\mathrm{a}}$ for both samples, it was possible to conclude that the bar is more fragile than the film. The lower values of $E_{\mathrm{a}}$ exhibited by the oriented film were attributed to its higher structural regularity when compared with the bar. In addition, the DSC results revealed the existence of rigid amorphous phase in semi-crystalline PET that increases with increasing crystallinity and/or orientation.

The use of TSR, in contrast to DSC, permitted the clear detection of the $T_{\mathrm{g}}$ for the semi-crystalline oriented PET film and the investigation of its glass transition dynamics. This shows the high sensitivity of this technique to locate the glass transition even for samples with crystallinity/orientation effects.

The results obtained in this work also seem to indicate that the compensation phenomenon is a pure mathematical consequence of the underlying process and does not have a true physical origin, because it is seen for two PET samples with distinct crystallinity and orientation, that the compensation lines tend to converge to the same point and that the compensation effect does not depend on the previous thermal history below $T_{\mathrm{g}}$ undergone by the material.

Finally, it has been shown that TSR is a suitable technique to monitor the structural relaxation process of PET. The characteristic parameters of the TSR 
curves vary with the ageing temperature $\left(T_{\mathrm{a}}\right)$ and ageing time $\left(t_{\mathrm{a}}\right)$. For a given ageing temperature, $E_{\mathrm{a}}$ decreases as $t_{\mathrm{a}}$ increases and $\log \tau_{0}$ increases as $t_{\mathrm{a}}$ increases, as is usual in compensation behaviour. The decrease in $\varepsilon_{0}$ with increasing $t_{\mathrm{a}}$ was explained by the stiffening of the material with ageing and the decrease of $T_{\text {max }}$ with increasing $t_{\text {a }}$ was interpreted in terms of the shift of the isolated retardation times towards lower values in the TS experiments.

\section{ACKNOWLEDGEMENTS}

NMA acknowledges the Foundation for Science and Technology (FCT) for financial support through grant PR AXIS XXI/BD/20327/99. Financial support for this work was also provided by FCT through the POCTI and FEDER programmes.

\section{REFERENCES}

1. N. M. ALVES, J. F. MANO and J. L. GÓMEZ RIBELLES: M acromol. Symp., 1999, 148, 437-554.

2. N. M. ALVES, J. F. MANO and J. L. GÓMEZ RIBELLES: Mat. Res. Innovat., 2001, 4, 170-178.

3. J. F. MANO: Thermochim. Acta, 1999, 332, 161-170.

4. C. LACABANNE, D. C. CHATAIN, J. C. MOMPAJENS, A. HILTNER and E. BAER: Solid State Commun., 1978, 27, 1055-1057.

5. C. LACABANNE, A. LAMURE, G. TEYSSEDRE, A. BERNÈS and M. MOURGUES: J. Non-Cryst. Solids, 1994, 172-174, 884-890.

6. B. B. SAUER, P. AVAKIAN, B. S. HSIAO and H. W. STAR KWEATHER: Macromolecules, 1990, 23, 5119-5126.

7. J. F. MANO, N. T. CORREIA and J. J. MOURA RAMOS: Polymer, 1994, 35, 3561-3564.

8. N. M. ALVES, J. F. MANO and J. L. GÓMEZ RIBELLES: J. Thermal Anal. Calorim., 2002, 70, 633-649.

9. N. M. ALVES, J. F. MANO and J. L. GÓMEZ RIBELLES: Polymer, 2001, 42, 4173-4180.

10. S. V. SHENOGIN, S. I. NAZARENKO, S. N. RUDNEV, E. F. OLEINIK and G. H. W. HÖHNE: Polym. Sci. Ser. B., 1997, 39, 486-492.

11. J. A. DIEGO, J. C. CAÑADAS, M. MUDARRA and J. BELANA: Polymer, 1999, 40, 5355-5363.

12. J. ZHAO, R. SONG, Z. ZHANG, X. LINGHU, Z. ZHENG and Q. FAN : Macromolecules, 2001, 30, 343-345.

13. I. M. WARD and D. W. HADLEY: 'An Introduction to the MechanicalProperties of Solid Polymers'; 1993, New York, John Wiley.

14. W. L. AKLONIS and W. J. MCKNIGHT: 'Introduction to Polymer Viscoelasticity'; 1983, New York, John Wiley.

15. E. DARGENT, J. GRENET and A. DAhoun: Polym. Eng. Sci., 1997, 37, 1853-1857.

16. E. NEAGU, P. PISSIS, L. APEKIS and J. L. GÓMEZ RIBELLES: $J$. Phys D: Appl. Phys., 1997, 30, 1551-1560.

17. J. J. MOURA RAMOS, J. F. MANO and B. B. SAUER: Polymer, 1997, 38, 1081-1089.

18. I. M. HODGE: J. Non-Cryst. Solids, 1994, 169, 211-266.

19. X. F. LU and J. N. HAY: Polymer, 2001, 42, 9423-9431.

20. B. B SAUER, W. G. KAMPERT, E. NEAL BLANCHARD, A. S THREEFOOT and B. S. HSIAO: Polymer, 2000, 41, 1099-1108.

21. Y. KONG and J. N. HAY: Polymer, 2003, 44, 623-633.

22. N. M. ALVES, J. F. MANO and J. L. GÓMEZ RIBELLES: Polymer, 2002, 43, 4111-4122.

23. J. DOBbertin, A. HENSEL and C. SCHICK: J. Therm. Anal., 1996, 47, 1027-1040.
24. B. WUNDERLICH: 'Macromolecular Physics'; 1980, New York: Academic Press.

25. C. M. ROlAnd and M. F. SONNENSChein: Polym. Eng. Sci., 1991, 31, 1434-1439.

26. E. DARGENT, C. CABOT, J. M. SAITER, J. BAYARD and J. GRENET: J. Therm. Anal., 1996, 47, 887-896.

27. J. MENCZEL and B. WUNDERLiCh: J. Polym. Sci. Polym. Lett. Ed., 1981, 19, 261-264.

28. R. J. SEYLER: J. Therm. Anal., 1997, 49, 491-498.

29. M. KATtAn, E. DARgent and J. GRenet: Polymer, 2002, 43 1399-1405.

30. I. ISHIDA, K. YAMAFUJI, H. ITO and M. TAKAYANAGI: KolloidZ. Z. Polym., 1962, 184, 97.

31. H. SUZU KI, J. GREBOWICZ and B. WUNDERLICH: Br. Polym. J., 1985, 17, 1-3

32. I. OKAZAKI and B. WUnderlich: J. Polym. Sci. Polym. Phys. Ed., 1996, 34, 2941-2952.

33. B. WUnderlich: Prog. Polym. Sci., 2003, 28, 383-450.

34. E. DARGENT, J. J. SANTAIS, J. M. SAITER, J. BAYARD and J. GRENET: J. Non-Cryst. Solids, 1994, 172-174, 1062-1065.

35. C. SCHICK, J. DOBBERTIN, M. PÖTTER, H. DEHNE, A. HENSEL, A. WURM, A M. GHONEIM and S. WEYER: J Therm. Anal., 1997, 49, 499-511.

36. J. C. COBURN and R. H. BOYD: Macromolecules, 1986, 19, $2238-2245$.

37. J. S. ZAROUlis and M. C. BOYCE: Polymer, 1997, 38, $1303-1315$

38. C. BUCCI, R. FIESCHI and G. GUIDI: Phys. Rev., 1966, 148, 816.

39. G. ADAM and J. H. GIBBS: J. Chem. Phys., 1965, 43, 139-146.

40. H. VOGEL: Phys. Z., 1921, 22, 645; G. A. FULCHER: J. Am. Chem. Soc., 1925, 8, 339; G. TAMMAN and W. Z. HESSE: Annorg. Allg. Chem., 1926, 156, 245.

41. N. M. ALVES, J. F. MANO and J. L. GÓMEZ RIBELleS: Polymer, 2002, 43, 3627-3633.

42. E. DARGENT, M. KATTAN, C. CABOT, P. LEBAUDY, J. LEDRU and J. GRenet: J. Appl. Polym. Sci., 1999, 74, 2716-2723.

43. R. SATOTO, J. MORIKAWA and T. HASHIMOTO: Polym. Int., 1999, 48, 509-514.

44. B. B. SAUER and Y. H. KIM: Macromolecules, 1997, 30, 3323-3328.

45 C. A. ANGELL: J. Non-Cryst. Solids, 1991, 131-133, 13-31.

46. N. M. ALVES, J. F. MANO and J. L. GÓMEZ RIBELLES: Polymer, accepted.

47. O. EXNER: in 'Progress in Organic Chemistry', Vol. 10, (Eds. A. S. Streitwieser Jr and R. W. Taft); 1973, New York, John Wiley.

48. A. BERNES, D. CHATAIN and C. LACABANNE: IEEE Trans. Electr. Insul., 1992, 27, 464

49. P. Mialhe: J. Phys. D, Appl. Phys., 1989, 22, 720.

50. R. R. KRUG, W. G. HUNTER and R. A. GRIEGER: Nature, 1976 , 261, 566.

51. M. ZIELIN SKI, T. SWIDERSKI and M. KRYSZEWSKI: Polymer, 1978, 19, 882

52. J. F. MANO, N. T. CORREIA, J. J, MOURA RAMOS, S. R. ANDREWS and G. WILliAM S: Liquid Crystals, 1996, 20, 201.

53. S. DOULUT, C. BACHARAN, P. DEMONT, A. BERNÈS and C. LACABANne: J. Non-Cryst. Solids, 1998, 235-237, 645.

54. B. E. READ: Polymer, 1989, 30, 1439

55. L. C. E. STRUIK: 'Physical Ageing in Amorphous Polymers and Other Materials'; 1978, Amsterdam, Elsevier.

56. J. BELANA, J. C. CAÑADAS, J. A. DIEG O, M. MUDARRA, R. DÍAZ, S. FRIEDERICHS, C. JAIMES and M. J. SANCHIS: Polym. Int., 1998, 46, 29.

57. J. C. CAÑADAS, J. A. DIEGO, M. MUDARRA and J. BELANA: Polymer, 1998, 39, 2795. 
Copyright of Plastics, Rubber \& Composites is the property of Maney Publishing and its content may not be copied or emailed to multiple sites or posted to a listserv without the copyright holder's express written permission. However, users may print, download, or email articles for individual use. 